\title{
EXPERIMENTAL FAILURE ANALYSIS OF SHEAR-CRITICAL ORDINARY AND STEEL-FIBRE REINFORCED CONCRETE BEAMS USING OPTICAL MEASUREMENT TECHNIQUES
}

\author{
KRISTOF DE WILDER*, PASCAL LAVA ${ }^{\dagger}$, EDWIN REYNDERS*, GUIDO DE ROECK* \\ AND LUCIE VANDEWALLE* \\ ${ }^{*}$ KU Leuven \\ Department of Civil Engineering \\ Kasteelpark Arenberg 40 box 2448 \\ Heverlee, Belgium \\ e-mail: Kristof.DeWilder@bwk.kuleuven.be \\ ${ }^{\dagger}$ KU Leuven - KULLOC Gent \\ Mechanics of Materials, Products and Processes Section \\ Gebroeders De Smetstraat 1 \\ Ghent, Belgium
}

Key words: Shear, Prestressed concrete, Steel fibre reinforced concrete, Digital Image Correlation, Bragg grated optical fibre

\begin{abstract}
Although the use of fibre reinforced concrete (FRC) for structural applications is continuously increasing, it is still limited with respect to its potentials. This can be mainly attributed to the lack of international building codes for FRC structural elements. This paper aims to contribute to the development of suitable design principles for shear in FRC elements by presenting the preliminary results of 6 full-scale pretensioned steel-fibre reinforced concrete members. The main investigated parameters are the amount of prestressing, the amount of shear reinforcement and the fibre dosage respectively. All specimens are subjected to a four-point bending test until failure. Traditional mechanical measurement devices are used in combination with advanced optical measurement systems (i.e. stereo-vision digital image correlation 3D DIC and Bragg grated optical fibres). Apart from the full-scale tests, a number of small-scale experimental investigations are performed to characterize the material properties. The experimentally determined results are compared to predictions using analytical models found in Eurocode 2 (EC2) and Model Code 2010 (MC2010). Based on the obtained full-field data from the DIC systems and the detailed deformation information obtained from the Bragg grated optical fibres, an assessment is made of the mechanical behaviour.
\end{abstract}

\section{INTRODUCTION}

A number of studies were already carried out to study the flexural behaviour of SFRC beam elements [1-7]. On the contrary, only a limited amount of research has been devoted to study the shear behaviour of beams where traditional shear reinforcement is (partly) replaced by steel fibres. Shear-critical structural concrete elements, i.e. elements failing due to shear, generally fail in a very brittle manner. These members could therefore specifically benefit from the enhanced post-cracking behaviour provided by the use of SFRC.

Noghabai [8] conducted several experimental tests on beams of different dimensions and shear spans and composed of different types 
of fibres. His results show that the presence of fibres is essential in the observed structural behaviour. Experimental work carried out by Meda et al. [9] indeed showed that the shear behaviour of fibre reinforced concrete beams without additional shear reinforcement is similar to or even better than that of beams with shear reinforcement. An extensive research program on steel fibre reinforced beams, carried out within the framework of a Brite Euram Program [12], showed that steel fibres can substitute the minimum shear reinforcement necessary in ordinary reinforced concrete members to ensure a ductile failure. This was recently reaffirmed by Kang et al. [13] and Abbas et al. [14]. However, conclusive experimental data on prestressed shear-critical steel fibre reinforced concrete is still absent in the literature.

Based on experimental evidence, it is thus currently established that steel fibres have a positive effect on the shear behaviour of structural concrete elements in both the serviceability limit state (SLS) and ultimate limit state (ULS). However, determining the actual contribution of the steel fibres to the overall shear capacity of full-scale elements still remains open for discussion. As a consequence, most proposed modeling procedures are empirical or semi-empirical design approaches based on linear and nonlinear regression analysis of experimental databases [13, 15, 16]. Moreover, these design procedures are mainly derived from experimental results on reinforced concrete members and their use is generally extrapolated to prestressed concrete elements. Applying these models to prestressed elements should thus be done with due caution.

This paper therefore aims to improve our understanding of the mechanical behaviour of shear in ordinary and steel-fibre reinforced prestressed concrete beams by presenting the preliminary results of the experimental investigation and subsequent analysis of 6 full-scale shear-critical prestressed steel-fibre reinforced concrete beams. In the first section, the experimental program is elaborated. Specific attention is given to the experimental setup and the use of advanced optical measurement methods (i.e. stereo-vision digital image correlation and Bragg grated optical fibres). Secondly, the full-scale results are presented and compared to analytical predictions according to Model Code 2010 and Eurocode 2. The obtained experimental displacement and deformation results are finally analysed to assess the mechanical response during the loading procedure.

\section{EXPERIMENTAL RESEARCH}

\subsection{Test Specimens}

Each specimen was labelled with the descriptive letter $B$ followed by a number ranging from 401 to 406. All specimens where characterized by an I-shaped cross section and were $7000 \mathrm{~mm}$ long, $630 \mathrm{~mm}$ high and had a flange width equal to $240 \mathrm{~mm}$. The web width was equal to $70 \mathrm{~mm}$. Each beam was prestressed using seven 7 -wire strands at the bottom and one 7-wire strand at the top (nominal diameter $12.5 \mathrm{~mm}$ ). All strands of specimens B401B403 were given an initial prestrain equal to $7.5 \times 10^{-3} \mathrm{~mm} / \mathrm{mm}\left(\sigma_{p 0}=1488 \mathrm{MPa}\right)$ whereas the initial prestrain given to the strands of specimens B404-B406 was equal to $3.8 \times 10^{-3}$ $\left(\sigma_{p 0}=750 \mathrm{MPa}\right)$. While it is uncommon in the industry to apply stress levels below the allowable, a reduced stress level was considered for beams B404-B406 to assess the influence of a varying prestressing force on the overall shear capacity while keeping the longitudinal reinforcement ratio constant.

Conventional shear reinforcement consisting of single-legged stirrups (nominal diameter $6 \mathrm{~mm}$ with a centre-to-centre distance equal to $150 \mathrm{~mm}$ ) was provided in specimens B401 and B404. Steel fibres (hooked end Dramix RC80/30-CP, length $30 \mathrm{~mm}$, diameter $0.38 \mathrm{~mm}$, tensile strength $3070 \mathrm{MPa}$ ) were added to the concrete mixture to replace the conventional shear reinforcement in the remaining specimens. Beams B402 and B405 were provided with $20 \mathrm{~kg} / \mathrm{m}^{3}$ whereas $40 \mathrm{~kg} / \mathrm{m}^{3}$ was provided in specimens B403 and B406. To avoid splitting failure at the end of the specimens due to the gradual development of the pre- 


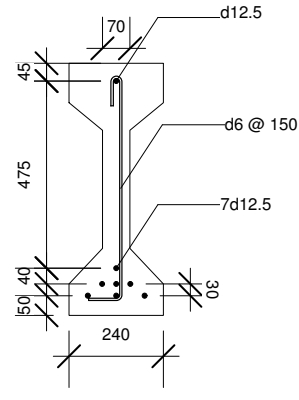

(a) B401-B404

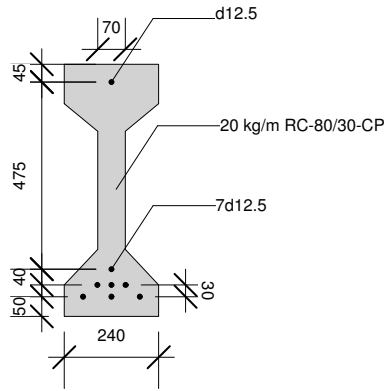

(b) B402-B405

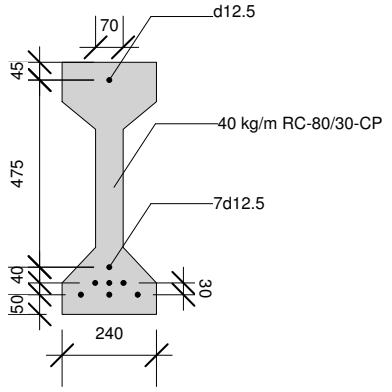

(c) B403-B406

Figure 1: Cross sections and reinforcement layout of the presented test specimens, gray indicates steel-fibre reinforced concrete (note: units in $[\mathrm{mm}]$ )

stressing force over the member's height, splitting reinforcement was provided consisting of closed double-legged stirrups (nominal diameter $8 \mathrm{~mm}$, centre-to-centre distance equal to $50 \mathrm{~mm}$ ). The geometry and reinforcement layout is presented in Fig. 1. Demountable mechanical strain gauge points were provided on each specimen to allow for the quantification of the immediate and time-dependent stress losses (assuming perfect bond between concrete matrix and prestressing strands). At the time of testing, it was found that $90 \%$ of the initial prestressing force was retained in the bottom strands whereas the stress level at the time of testing in the top prestressing strands was found to be equal to $95 \%$ of the initial stress.

\subsection{Materials}

A self-compacting concrete mixture was used to cast the presented test specimens. Additional mechanical vibration applied onto the steel formwork was used to ensure a good compaction of specimens B402-B403 and B405B406. The mixture properties are listed in Table 1. All adopted mixtures were designed to have a characteristic cylindrical compressive strength $f_{c k}$ of $50 \mathrm{MPa}$. All mixtures were made in volumes of $1.5 \mathrm{~m}^{3}$. Together with each specimen, 3 cubes $(150 \times 150 \times 150$ $\left.\mathrm{mm}^{3}\right)$, three prisms $\left(150 \times 150 \times 600 \mathrm{~mm}^{3}\right)$ and three cylinders (diameter/height equal to $150 \mathrm{~mm} / 300 \mathrm{~mm}$ ) were cast to determine the mean cube compressive strength $f_{c m, c u b e}$ the mean cylindrical compressive strength $f_{\mathrm{cm}}$, the mean secant modulus of elasticity $E_{c m}$, the mean flexural tensile strength $f_{c t m, f l}$ and the residual flexural tensile strength $f_{R, j}$ (with $j=$ $1,2,3,4)$ in the case of steel fibre reinforced concrete. The experimentally determined material properties are listed in Table 2. The mean concrete density $\rho_{m}$ and the age at the day of testing is also presented in Table 2 . Fig. 2 presents the measured $\sigma_{N}$-CMOD (Crack Mouth Opening Displacement) for the adopted concrete mixture with $20 \mathrm{~kg} / \mathrm{m}^{3}$ and $40 \mathrm{~kg} / \mathrm{m}^{3}$ respectively. The derived residual flexural tensile strengths $f_{R, j}$ (with $j=1,2,3,4$ ) are presented in Table 3 .

Table 3: Experimentally determined mean residual flexural tensile strength of specimens B402-B403 (Mix 2) and B405-B406 (Mix 3), refer to Table 1

\begin{tabular}{lllll}
\hline$j$ & Property & Unit & Mix 2 & Mix 3 \\
\hline 1 & $\bar{f}_{R 1}$ & {$[\mathrm{MPa}]$} & 4.14 & 9.65 \\
& $s_{f_{R 1}}$ & {$[\mathrm{MPa}]$} & 1.13 & 1.46 \\
2 & $\bar{f}_{R 2}$ & {$[\mathrm{MPa}]$} & 4.53 & 9.10 \\
& $s_{f_{R 2}}$ & {$[\mathrm{MPa}]$} & 1.18 & 1.20 \\
3 & $\bar{f}_{R 3}$ & {$[\mathrm{MPa}]$} & 4.14 & 7.95 \\
& $s_{f_{R 3}}$ & {$[\mathrm{MPa}]$} & 0.91 & 1.07 \\
4 & $\bar{f}_{R 4}$ & {$[\mathrm{MPa}]$} & 3.58 & 6.76 \\
& $s_{f_{R 4}}$ & {$[\mathrm{MPa}]$} & 0.83 & 0.93 \\
\hline
\end{tabular}

Note: $\bar{f}_{R j}$ indicates mean value of $f_{R j}$;

$s_{f_{R j}}$ denotes standard deviation 
Table 1: Mixture compositions for the presented test specimens

\begin{tabular}{llll}
\hline Material & $\begin{array}{l}\text { Mixture 1 (B401, B404) } \\
{\left[\mathrm{kg} / \mathrm{m}^{3}\right]}\end{array}$ & $\begin{array}{l}\text { Mixture 2 (B402, B405) } \\
{\left[\mathrm{kg} / \mathrm{m}^{3}\right]}\end{array}$ & $\begin{array}{l}\text { Mixture 3 (B403, B406) } \\
{\left[\mathrm{kg} / \mathrm{m}^{3}\right]}\end{array}$ \\
\hline CEM I 52.5 R & 374.0 & 375.3 & 306.7 \\
Blast furnace slag & 0.0 & 0.0 & 128.7 \\
Sand 0/2 & 700.0 & 700.0 & 680.7 \\
Limestone gravel 2/12 & 1123.0 & 1090.7 & 1006.0 \\
Water & 106.7 & 107.3 & 122.7 \\
Limestone filler & 130.7 & 131.3 & 149.3 \\
High-range water reducer & 5.4 & 5.4 & 5.6 \\
Steel fibres RC-80/30-CP & 0.0 & 2.0 & 40.0 \\
\hline
\end{tabular}

Table 2: Experimentally determined concrete material properties for the reported test specimens

\begin{tabular}{lllllll}
\hline Specimen & $\begin{array}{l}f_{c m, c u b e}(\#, \mathrm{~s}) \\
{[\mathrm{MPa}]}\end{array}$ & $\begin{array}{l}f_{c m}(\#, \mathrm{~s}) \\
{[\mathrm{MPa}]}\end{array}$ & $\begin{array}{l}E_{c m}(\#, \mathrm{~s}) \\
{[\mathrm{GPa}]}\end{array}$ & $\begin{array}{l}f_{c t m, f l}(\#, \mathrm{~s}) \\
{[\mathrm{MPa}]}\end{array}$ & $\begin{array}{l}\rho_{m}(\#, \mathrm{~s}) \\
{\left[\mathrm{kg} / \mathrm{m}^{3}\right]}\end{array}$ & $\begin{array}{l}\text { Age } \\
\text { [days] }\end{array}$ \\
\hline B401 & 79.4 & 75.6 & 45.4 & 9.5 & 2429.1 & 38 \\
& $(3,3.48)$ & $(3,0.94)$ & $(3,1.89)$ & $(3,0.40)$ & $(3,17.7)$ & \\
B402 & 65.0 & 73.8 & 39.5 & 5.0 & 2379.8 & 43 \\
& $(3,1.28)$ & $(3,7.14)$ & $(3,1.05)$ & $(3,0.24)$ & $(3,18.9)$ & \\
B403 & 67.7 & 69.7 & 41.1 & 5.5 & 2424.7 & 47 \\
& $(3,1.02)$ & $(3,4.63)$ & $(3,1.21)$ & $(3,0.18)$ & $(3,29.1)$ & \\
B404 & 97.9 & 68.1 & 47.7 & 5.5 & 2449.4 & 52 \\
& $(3,0.85)$ & $(2,-)$ & $(2,-)$ & $(3,0.18)$ & $(3,29.1)$ & \\
B405 & 78.1 & 79.4 & 41.1 & 4.2 & 2379.3 & 56 \\
& $(3,1.18)$ & $(3,3.50)$ & $(3,1.10)$ & $(3,0.17)$ & $(3,2.6)$ & \\
B406 & 89.5 & 77.4 & 44.5 & 5.6 & 2406.9 & 57 \\
& $(3,0.12)$ & $(3,12.3)$ & $(3,4.6)$ & $(3,0.28)$ & $(3,18.1)$ & \\
\hline
\end{tabular}

Note: ${ }^{\bullet} \#$ indicates the number of tested specimens and $s$ represents the standard deviation

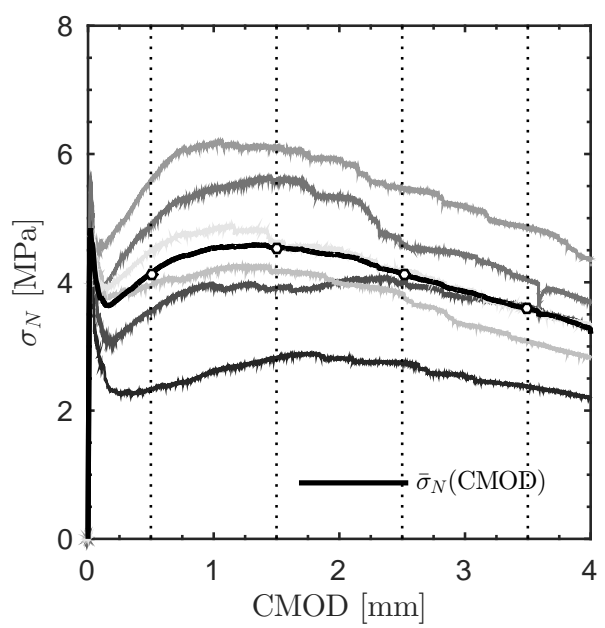

(a) $V_{f}=20 \mathrm{~kg} / \mathrm{m}^{3}$

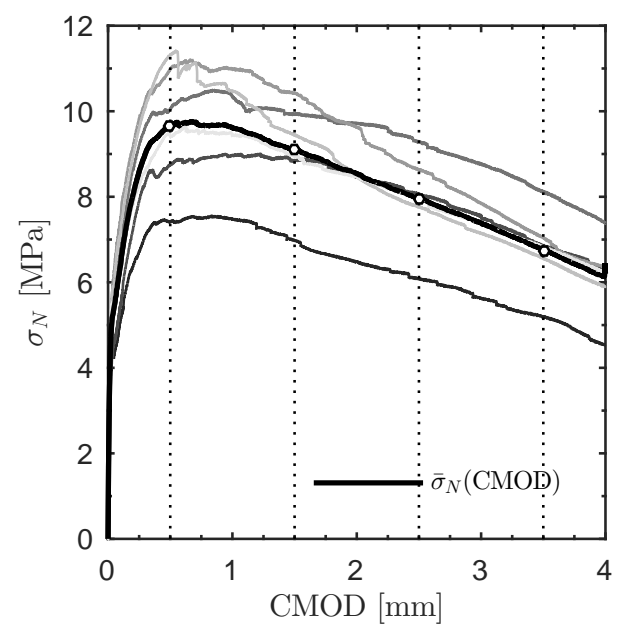

Figure 2: Nominal stress $\sigma_{N}$ as a function of CMOD for (a) beams B402, B405 and (b) B403, B406 with indication of the average nominal stress $\bar{\sigma}_{N}$ as a function of the CMOD 
Tensile tests were performed on the reinforcement steel to determine the mean yield strength $f_{y m}$, the mean ultimate tensile strength $f_{t m}$ with the corresponding strain at failure $\epsilon_{s u}$ and the modulus of elasticity $E_{s}$. The same properties of the prestressing steel were taken from the technical information provided by the precast manufacturer. The results are shown in Table 4.

Table 4: Reinforcement properties

\begin{tabular}{lllllll}
\hline Reinf. type & $d_{p}$ & $E_{p}$ & \multicolumn{2}{c}{$f_{p 0.1 m} f_{p m}$} & $\epsilon_{p u}$ \\
& $d_{s}$ & $E_{s}$ & $f_{y m}$ & $f t m$ & $\epsilon_{s u}$ \\
& {$[\mathrm{~mm}]$} & {$[\mathrm{GPa}]$} & {$[\mathrm{MPa}]$} & {$[\mathrm{MPa}]$} & {$[\%]$} \\
\hline Top prestr. & 12.5 & 198.0 & 1737 & 1930 & 5.20 \\
Bot. prestr. & 12.5 & 198.0 & 1737 & 1930 & 5.20 \\
Shear reinf. & 6.0 & 210.0 & 608 & 636 & 2.73 \\
Split. reinf. & 8.0 & 203.0 & 542 & 603 & 5.97 \\
\hline
\end{tabular}

\subsection{Experimental setup}

All specimens were subjected to a four-point bending test using a hydraulic press (Instron, maximum capacity $2500 \mathrm{kN}$ ), schematically depicted in Fig. 3 (a-b) and shown in Fig. 4 (a). All tests were carried out in load-control following a progressive damage loading scheme. Fig. 5 (a) shows a typical progressive damage loading scheme as a function of time whereas Fig. 5 (b) presents the corresponding loaddisplacement response curve. The loading rate $\dot{P}$ was equal to $0.25 \mathrm{kN} / \mathrm{s}$ (shear force rate $\dot{V}$ equal to $0.125 \mathrm{kN} / \mathrm{s}$ ) whereas the total unloading rate was equal to $0.25 \mathrm{kN} / \mathrm{s}$ (first cycle) or $1.00 \mathrm{kN} / \mathrm{s}$ (second cycle). The distance between the support points is $5000 \mathrm{~mm}$. The distance outside the support points was therefore equal to $1000 \mathrm{~mm}$ at each end. This allows the authors to study shear outside the length needed for the prestressing force to gradually develop over the member's height. The shear span $a$ was equal to $2200 \mathrm{~mm}$ for all specimens. This results in a shear span-to-effective depth ratio $\frac{a}{d}$ equal to 3.95 .
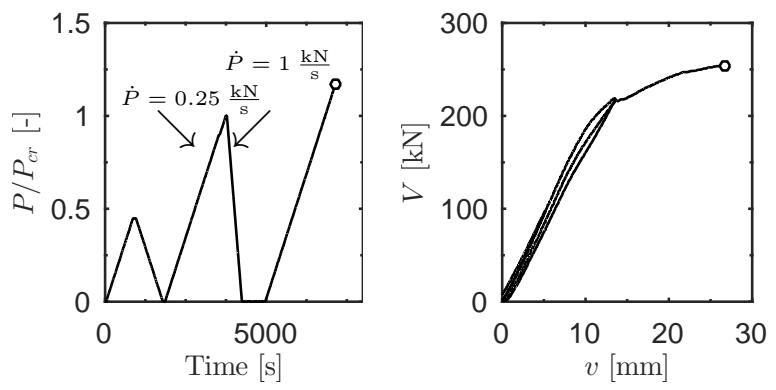

Figure 5: (a) Typical applied progressive damage loading scheme as a function of time $\left(P_{c r}\right.$ indicates the cracking load; (b) corresponding shear force-vertical displacement curve at the location of the loading point (here depicted for beam B403, o indicates failure)

\subsection{Instrumentation and adopted optical measurement techniques}

Continuous measurements of all specimens were measured using LVDTs and an optical photoelectric sensor (Baumer Photoelctric OADM 12U6460, resolution $96 \times 10^{-3} \mathrm{~mm}$, see Fig. 3 (a)). However, if the mechanical behaviour is to be thoroughly understood, more detailed displacement and deformation data is required over the entire loading range. Setups employing the aforementioned measurement methods rapidly become cumbersome and time consuming. Therefore, advanced optical measurement methods were employed to facilitate the mechanical characterisation of the presented test beams during the applied loading procedure. Two Stereo-vision digital image correlation (3D-DIC) systems were used to analyse the full-field displacement and deformation field, refer to Fig. 3 (a). Bragg grated optical fibres were used during the experiments on specimens B403 (top flange) and B404 (top and bottom flange) to accurately measure the horizontal strains in the flanges, refer to Fig. 3(b). In the following, the adopted measurement techniques will be briefly presented.

\subsubsection{Stereo-vision digital image correla- tion (3D-DIC)}

As an optical full-field measurement technique, digital image correlation has proven to be an ideal tool to a wide array of applications, including the identification of the mechanical 


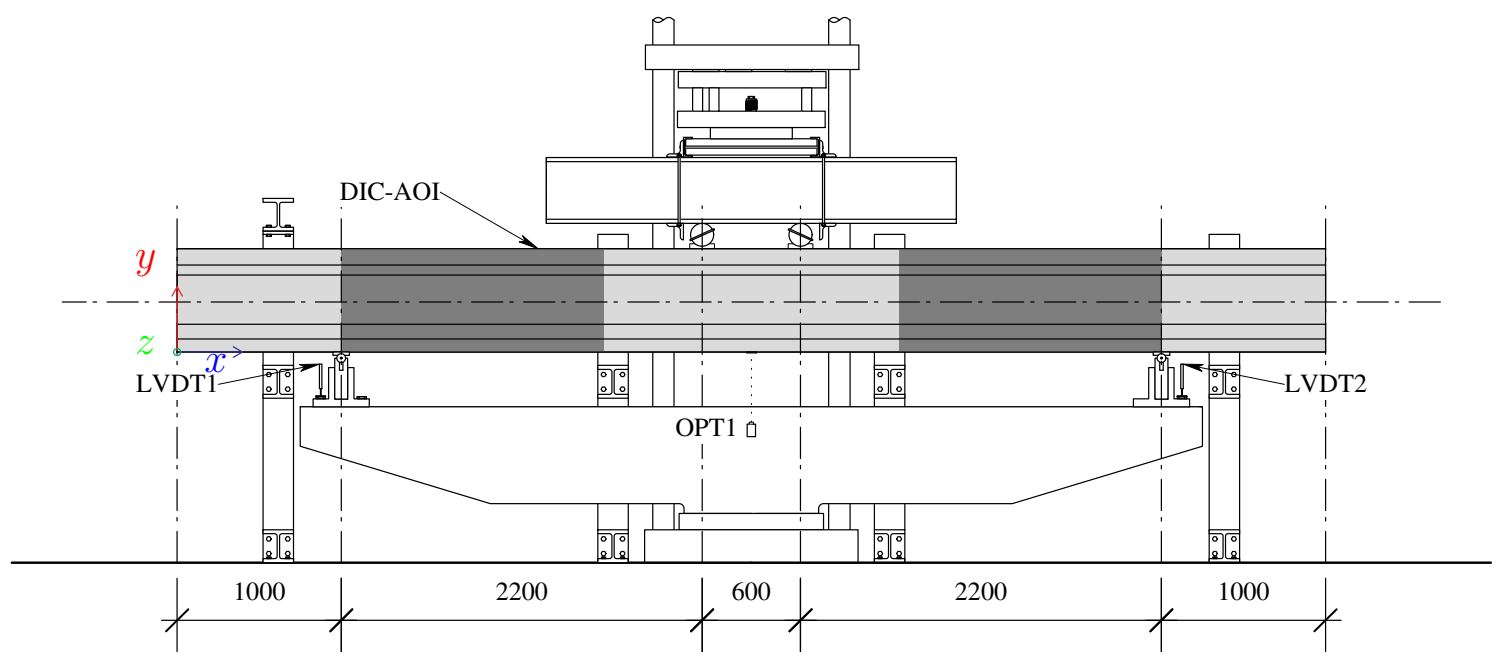

(a) Front view of experimental setup

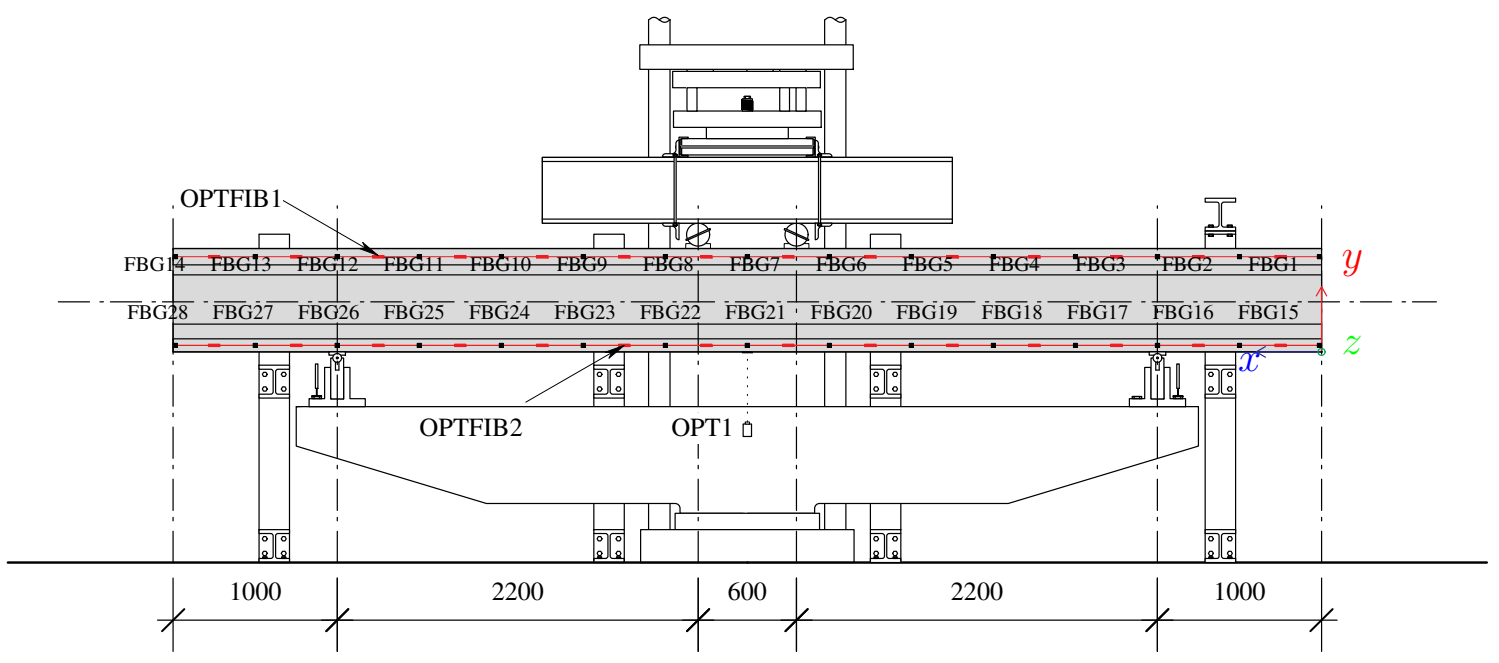

(b) Back view of experimental setup

Figure 3: Experimental setup for the presented test beams with indication of the optical measurement instrumentation (refer to Section 2.4.1 2.4.2.

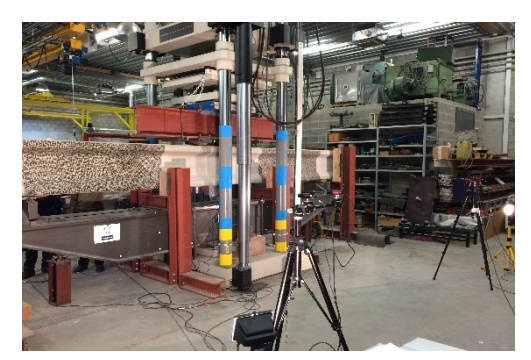

(a)

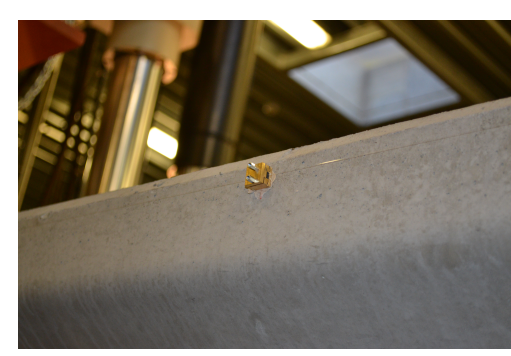

(b)

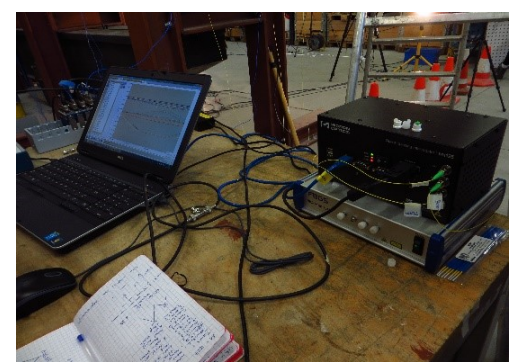

(c)

Figure 4: Experimental setup: (a) Four-point bending test and 3D-DIC instrumenation, refer to Section 2.4.1, (b) Mechanically anchored Bragg grated optical fibre (B404), refer to Sec. 2.4.2. (c) High-resolution FBG interrogator 
material behaviour through inverse modelling, structural health monitoring, and the study of the deformation characteristics of a wide range of materials. The basic principle behind this technique is to calculate the displacements on the surface of an object by taking digital images of a gray speckle pattern in the undeformed and deformed state. Three main steps are usually followed: (1) capture images; (2) correlation process; and (3) post-processing phase.

In the reported study, both zones where a shear force occurs were investigated by using two-stereo-vision DIC systems. Each zone under investigation measured approximately $1500 \mathrm{~mm}$ by $630 \mathrm{~mm}$. Each system consists of two CCD 8-bit cameras (AVT Stingray F201$\mathrm{B}, 12 \mathrm{~mm}$ focal length lens) mounted on a tripod. The cameras were located at a perpendicular distance of $2700 \mathrm{~mm}$ from the web of the specimens. The image acquisition rate was equal to $1 \mathrm{~Hz}$ with a camera exposure time of $12 \mathrm{~ms}$. Each image is synchronized with the analogue data (applied force and corresponding stroke) of the hydraulic press

In this contribution, a traditional subsetbased method was employed. The formalism is clearly explained by Lava et. al. [17]. Maximization of the degree of similarity between two subsets is obtained by adopting the Zero-Normalised Sum of Squared Differences (ZNSSD) correlation algorithm. The size of the subset was chosen equal to 27 px by 27 px (step size $3 \mathrm{px}$ ) where the physical dimension of one pixel approximates $1 \mathrm{~mm}$. Due to the large zone under investigation a relatively large speckle size is required. Moreover, the same speckle pattern must be applied in a controllable way onto each specimen to obtain the same level of accuracy and precision for all tests. Therefore, a numerical technique based on image processing and Fourier transform [18] in combination with a novel stencil printing technique has been adopted. This allows the authors to apply a tailor-made speckle pattern with a controllable speckle size and spatial distribution in a repeatable way onto each specimen. More detailed information is presented by De Wilder et al. [19].
The correlation procedure and the postprocessing is done using the in-house developed Mat ch ID software [17]. For the reported setup, the standard deviation of the in-plane displacement components $u_{i}$ (with $i=x, y$ ) was found to be equal to $17 \times 10^{-3} \mathrm{~mm}$ respectively $8 \times 10^{-3} \mathrm{~mm}$. The standard deviation of the outof-plane component was an order of magnitude higher (equal to $101 \times 10^{-3} \mathrm{~mm}$. The latter is less important for the reported investigations.

\subsubsection{Bragg grated optical fibres (FBG)}

Strain monitoring with optical fibres engraved with Bragg gratings relies on the analysis of the wavelength spectrum which is reflected by the Bragg gratings. If a change in length of the optical fibre occurs, a shift in the reflected wavelength is induced where a positive shift in wavelength is related to elongation of the fibre. Here, one (top flange, B403) or two (top and bottom flange, B404) optical fibres (FOS\&S, type SMW-01) based on Draw Tower Grating technology were applied, refer to Fig. 3 (b). The optical fibres have a primary ORMOCER coating. A high resolution FBG interrogator was applied for readouts of wavelengths between $1525 \mathrm{~nm}$ and $1565 \mathrm{~nm}$. Each optical fibre was equipped with 14 FBG sensors with a base length of $500 \mathrm{~mm}$. Each fibre is mechanically fixed into brass anchoring blocks, refer to Fig. 4 (b), which are glued onto the concrete side surface using a two-component adhesive. This setup allows for the fibre to be removed prior to failure to avoid damage. Finally, an extruded polystyrene cover was placed over the fibres to thermally shield the sensors from the environment. The strain resolution of the presented setups is approximately equal to $1 \mu \mathrm{S}$.

\section{FULL-SCALE EXPERIMENTAL RE- SULTS}

This section presents the experimentally observed structural behaviour. Fig. 6 (ab) present the observed load-displacement response curves at the location of the applied point loads. Fig 6 (a-b) clearly shows that all specimens exhibit a profound post-cracking be- 


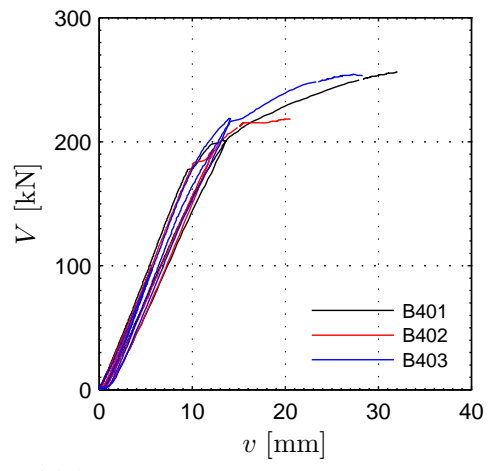

(a) B401-B403

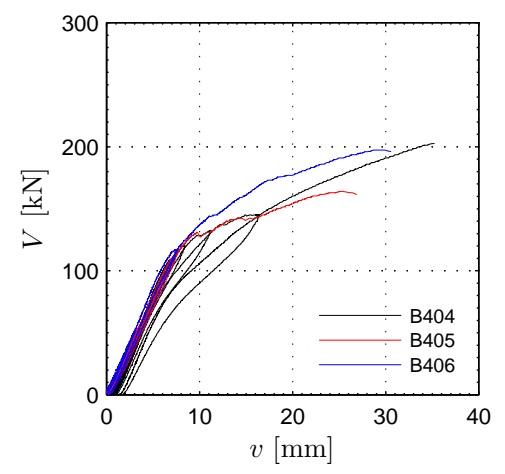

(b) B404-B406

Figure 6: Experimentally determined load-displacement response curves at the location of the point loads for (a) beams B401-B403; (b) beams B404-406

haviour, even for highly prestressed specimens with a relatively low fibre dosage, refer to specimen B402. All specimens were designed to fail in shear. Indeed, a shear failure mode, i.e. diagonal tension failure (S-DT), was encountered for all specimens. Severe web cracking led to yielding and rupture of the shear reinforcement elements for specimens B401 and B404. The steel fibres of specimens B402-B403 and B405B406 were found to be pulled out of the concrete matrix at failure. Fibre rupture was not encountered during the experiments. The experimentally observed failure mode for specimens with and without fibres is presented in Fig. 7)(a-b).

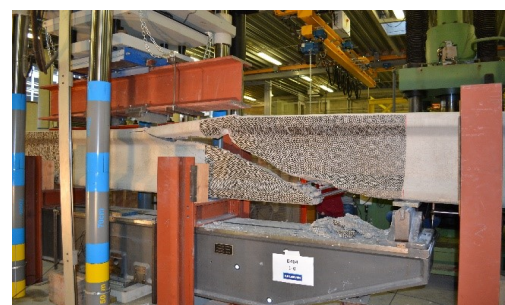

(a) Shear failure mode of B404

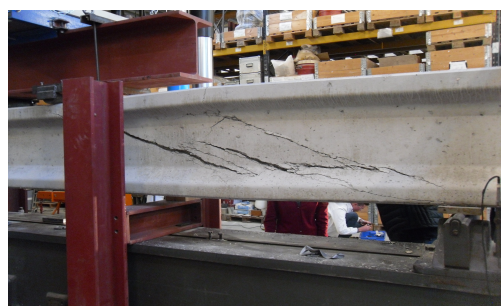

(b) Shear failure mode of B403

Figure 7: Typical failure modes for the test beams
Table 5 presents the experimentally observed failure load and failure mode properties for each test specimen, compared to analytical predictions according to Eurocode 2 (EC2) [20] and Model Code 2010 (MC2010) [21]. For beams without fibres and with shear reinforcement (B401 and B404), the shear design procedure of EC2 is used. Since EC2 does not currently provide a design procedure for SFRC beams, MC2010 is used for the beams with fibres (B402B403 and B404B405). For the estimation of the actual failure load, the partial safety factors are omitted and the average material properties, refer to Tables 2 3, are used. Since the amount of traditional shear reinforcement is relatively low, yielding of the shear reinforcement occurs prior to crushing of the compressive struts. Hence, the shear capacity $V_{R}$ of specimens B401 and B404 is to be determined using Eq. (1).

$$
V_{R}=V_{R, s}=\frac{A_{s w}}{s} z f_{y m} \cot \theta
$$

In Eq. (1), $\frac{A_{s w}}{s}$ is the amount of shear reinforcement per unit length, $z$ is the internal lever arm (taken equal to $0.9 d$ ), $f_{y m}$ is the mean yield stress of the shear reinforcement and $\theta$ is the angle between the horizontal and the inclined compressive stress field. The minimum allowable value (thus maximum allowable value of $\cot \theta)$ is adopted here and is determined using Eq. (2) [22] (where $\sigma_{c p}$ is the average stress due 
to the applied prestressing force).

$$
\cot \theta_{\max }=\left(2+\frac{0.15 \sigma_{c p} b_{w} d}{\frac{A_{s w}}{s} z f_{y m}}\right) \leq 3
$$

The shear capacity of members with fibres and conventional longitudinal reinforcement and without shear reinforcement $V_{R, F}$ is given by Eq. (3). This model is based on the shear capacity of plain concrete (as used in EC2), including a contribution of the distributed fibres by increasing the longitudinal reinforcement ratio with a factor that takes into account the toughness properties, i.e. the residual postcracking tensile strength, of FRC [23].

$$
\begin{array}{r}
V_{R}=V_{R, F}=\left[0.18\left(1+\sqrt{\frac{200}{d}}\right) \times\right. \\
\left(100 \rho_{l}\left(1+7.5 \frac{f_{\text {Ftum }}}{f_{c t m}}\right) f_{c m}\right)^{\frac{1}{3}}+ \\
\left.0.15 \sigma_{c p}\right] b_{w} d \\
\geq V_{R, F \min }
\end{array}
$$

In Eq. (3), $f_{\text {Ftum }}$ denotes the mean ultimate residual tensile strength for FRC, by considering the linear model presented in Eq. (4) whereas $f_{c t m}$ can be derived from $f_{c t m, f l}$ based on [24]. The maximum crack opening $w_{u}$ is equal to $1.5 \mathrm{~mm}$ and $\mathrm{CMOD}_{3}$ is $2.5 \mathrm{~mm}$. The mean flexural tensile strengths $f_{R m, 1}$ and $f_{R m, 3}$ were presented in Table 3 .

$$
\begin{aligned}
& f_{\text {Ftum }}= 0.45 f_{R m, 1}-\frac{w_{u}}{\mathrm{CMOD}_{3}} \times \\
&\left(0.65 f_{R m, 1}-0.5 f_{R m, 3}\right) \geq 0
\end{aligned}
$$

Table 5: Experimentally determined and analytically predicted failure mode (FM) and failure mode properties for each test specimen

\begin{tabular}{llllll}
\hline Beam & \multicolumn{3}{l}{ Experiment } & \multicolumn{3}{l}{ Prediction } \\
\cline { 2 - 6 } & & & & & \\
& $V_{u, \exp }$ & FM & $V_{u, \text { pred }}$ & FM & $\frac{V_{u, \text { exp }}}{V_{u, \text { pred }}}$ \\
& {$[\mathrm{kN}]$} & {$[-]$} & {$[\mathrm{kN}]$} & {$[-]$} & {$[-]$} \\
\hline B401 & 256.4 & S-DT & 172.4 & $\mathrm{~S}$ & 1.49 \\
B402 & 218.5 & S-DT & 158.5 & S & 1.38 \\
B403 & 254.4 & S-DT & 180.3 & S & 1.41 \\
B404 & 202.5 & S-DT & 150.7 & S & 1.34 \\
B405 & 164.1 & S-DT & 137.6 & S & 1.19 \\
B406 & 197.4 & S-DT & 146.5 & S & 1.35 \\
\hline & & & Mean & & $\mathbf{1 . 3 6}$ \\
& & & COV & & $\mathbf{7 . 2} \%$ \\
\hline
\end{tabular}

From the results presented in Table 5 and Fig. 6, following preliminary conclusions can be made.

1. An increased prestressing force, with a constant longitudinal reinforcement ratio, results in an increased shear capacity for specimens with (B401-B404) and without (B402-B405, B403-B406) shear reinforcement. An increased amount of fibres, for specimens with a constant prestressing force and without shear reinforcement, also results in a higher shear capacity (B402-B403, B405-B406), as expected.

2. Although all specimens failed due to shear, a clear distinction has to be made between the failure development of beams with shear reinforcement and beams with fibres. Multiple cracks occur for elements B402-B403 and B405-B406 (with fibres) whereas one major crack where all the deformation is localized is observed for beams B401 and B404 (with conventional shear reinforcement). Failure of specimens B401 and B404 is very brittle, highly energy releasing and occurs without the possibility of redistribution of internal forces. Failure of fibre 
reinforced specimens on the contrary is more ductile, even though a shear failure mode is observed, and redistribution of internal forces is to some extent possible.

3. The predicted failure loads are always an underestimation of the experimentally observed ones. Therefore, the design procedures of Eurocode 2 and Model Code 2010 result in highly conservative failure loads, even if partial safety factors are omitted and average material properties are used instead of design values. The mean experimental-to-predicted failure ratio is 1.36 , with a coefficient of variation of $7.2 \%$ and a relatively high correlation of 0.98 .

\section{DISCUSSION}

This section further explores the experimental displacement and deformation data, obtained from the 3D-DIC and FBG systems, to further investigate the discrepancy between the experimental results and analytical calculations presented in Table 5. Firstly, the conventionally reinforced specimens B401 and B404 are scrutinized. The model for shear adopted by EC 2, referred to as the variable angle truss model (VATM), assumes that the mechanical behaviour of a cracked structural concrete member can be represented by a parallel chord truss. The horizontal top and and bottom chords resist the applied bending moment whereas a set of inclined compressive struts and (vertical) tension ties resist the applied shear force. This model assumption can be assessed using the FBG strain data. Fig. 8 (b-c) show the measured horizontal deformation due to the applied loading at the top and bottom flange during one loading cycle, depicted in Fig. 8(a). From these measurements, the evolution of the distance between the most compressed fibre and the unstrained fibre $y_{\varepsilon}$ as a function of the length along the beam can be assessed. The typical results for one load cycle are presented in Fig. 8 (d) for specimen B404. From Fig. 8 (d) a nearly parabolic course of the distance between the most compressed fibre and the unstrained fibre can be noticed. Near the support points, this distance becomes larger whereas the value of $y_{\varepsilon}$ is the smallest in the middle of the span. Hence, the internal lever arm between the compressive and tensile force decreases and arch or direct strut action is activated. The latter contributed to the overall shear capacity and could explain why the VATM adopted from EC 2 performs poorly in estimating the total shear capacity. However, it is generally believed that arch or direct strut action is only significant for specimens with a shear span-to-effective depth ratio lower than 2.5. Here, the shear span to effective depth ratio is equal to 3.95

Finally, the experimental results of the steelfibre reinforced concrete specimens can be analysed. Since full-field displacement data is available from the 3D-DIC measurements, the actual crack width of the critical shear crack, i.e. the crack where eventually failure was initiated, can be evaluated. Based on the nominal stress-CMOD relationship, refer to Fig. 2 (ab), the experimental fibre contribution can be estimated. Fig. 9 shows the typical vertical displacement field $\mathbf{u}_{y}(x, y, z)$ near failure as a function of the surface coordinates of specimen B402. Based on the measured 3D displacement field, the crack widths can be determined, assuming that the entire deformation is located in the crack. Therefore, 6 virtual extensometers (referred to as $A 1 A 2-F 1 F 2$, left to right on Fig.9(a)) were placed perpendicularly over the critical shear crack. The cracking pattern at failure is also depicted in Fig. 9 (b). The measured crack width prior to failure is presented in Fig. 9 (c) whereas the corresponding nominal stress $\sigma_{N}$ is plotted in Fig. 9 (d). After failure, cores (diameter $113 \mathrm{~mm}$ ) were drilled to investigate the fibre orientation and fibre distribution. The locations of the drilled cores for specimens B402 are also indicated in Fig. 9 (b). A random fibre orientation and even distribution was observed along the critical shear crack. Given the critical shear crack geometry and inclination (crack length approximately $1020 \mathrm{~mm}$, mean 
(a)
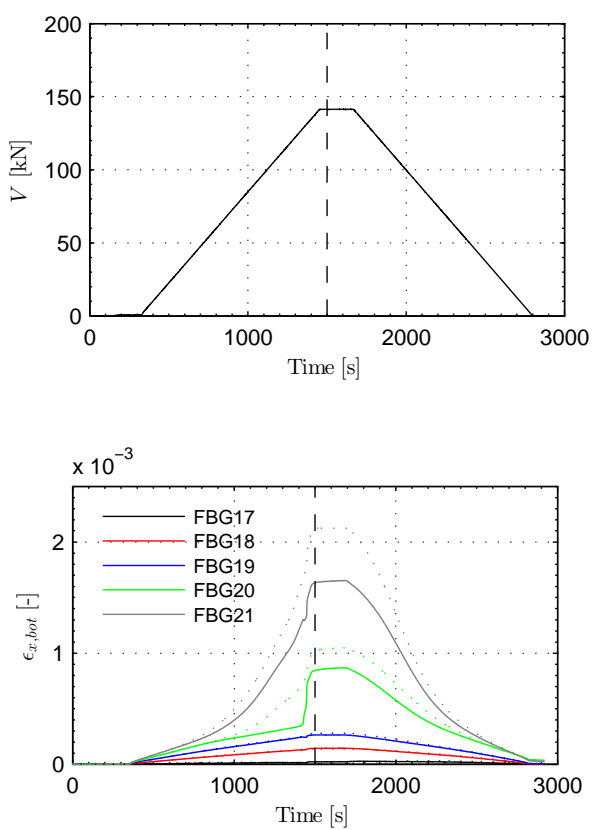

(c)

Figure 8: Deformation analysis of B404: (a) Applied shear force $V$ as a function of time; (b) Horizontal strain in the top flange $\epsilon_{x, t o p}$ as a function of time (symmetrical FBGs are indicated with a dotted line); (c) Horizontal strain in the bottom flange $\epsilon_{x, b o t}$ as a function of time; (d) Distance $y_{\varepsilon}$ as a function of the position along the $x$-axis, refer to Fig. 3 (a-b) at $V=141 \mathrm{kN}$ (indicated with a dashed line in (a-c) (location of loading points indicated with a red dotted line)

crack inclination $14.5^{\circ}$, refer to Fig. 9 (b)), a lower bound for the fibre contribution of specimen B402 is $138.3 \mathrm{kN}$ (adopting a residual stress value equal to $2 \mathrm{MPa})$. This observed value is significantly higher than the fibre contribution according to Eq. (3) found in Model Code 2010. The latter can be found by subtracting the shear capacity of the same specimen without fibres from the shear capacity obtained using Eq. (3). A fibre contribution of $37.2 \mathrm{kN}$ was found accordingly for specimen B402. Similar significant underestimations of the fibre contributions were found for the remaining fibre reinforced prestressed specimens. It can thus be concluded that the contribution of the steel fibres to the overall shear capacity is severely underestimated using Eq. (3) which, together with the earlier determined arching action, could provide a plausible explanation for the poor estimation of the shear capacity of the presented steel fibre reinforced test beams.

\section{CONCLUSIONS}

This paper aimed to investigate the mechanical behaviour of shear-critical prestressed steel-

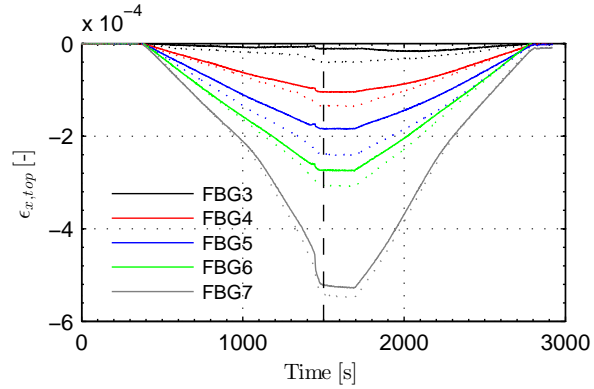

(b)

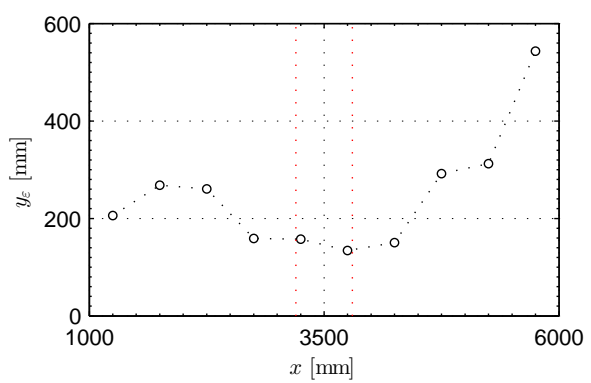

(d)

fibre reinforced concrete beams using advanced optical measurement methods. Six full-scale specimens were tested until failure following a four-point bending test setup with a progressive damage loading procedure. The main investigated variables are the amount of prestressing, the amount of shear reinforcement and the fibre dosage respectively. Both the stereo-vision digital image correlation technique and Bragg grated optical fibres were adopted to generate valuable displacement and deformation data which allow for a better insight in the mechanical behaviour of the presented test beams.

All presented test beams failed due to shear in a diagonal tension failure mode. The experimental results were compared to analytical calculations using both EC 2 and MC 2010. A severe underestimation of the actual failure load was found. Based on the deformation data obtained from the Bragg grated optical fibres, it was found that arching action is an important bearing mechanism and could explain the discrepancy between the experimental results and predictions for the ordinary prestressed con- 


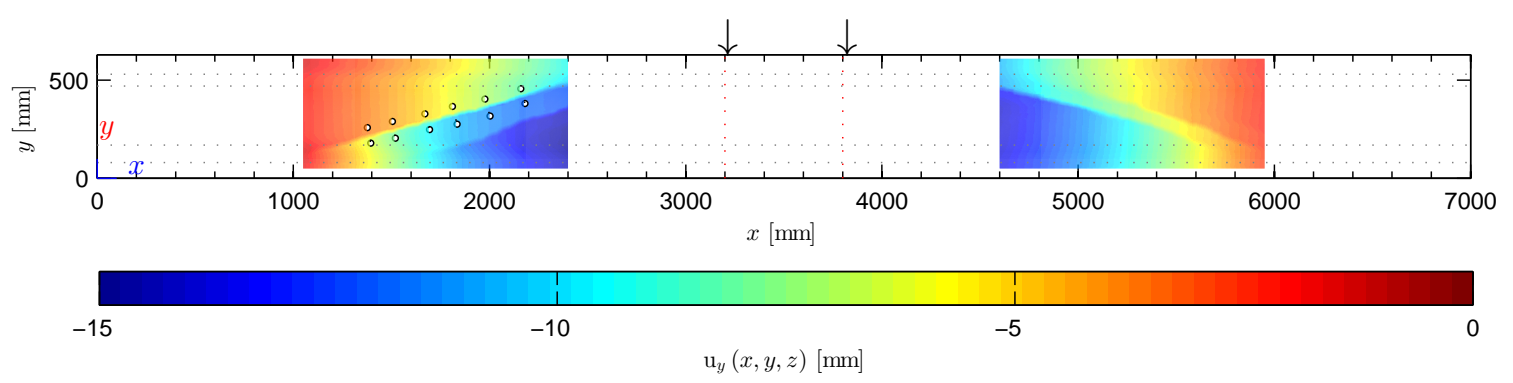

(a)

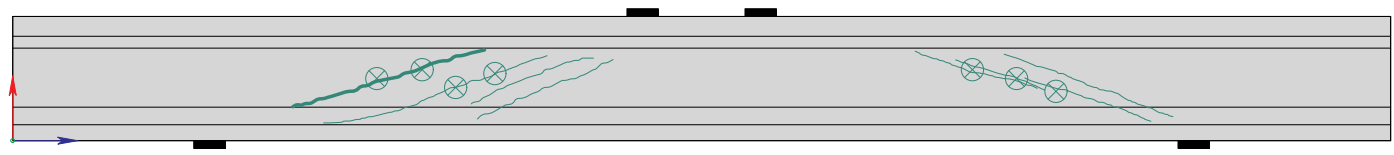

(b)

(c)

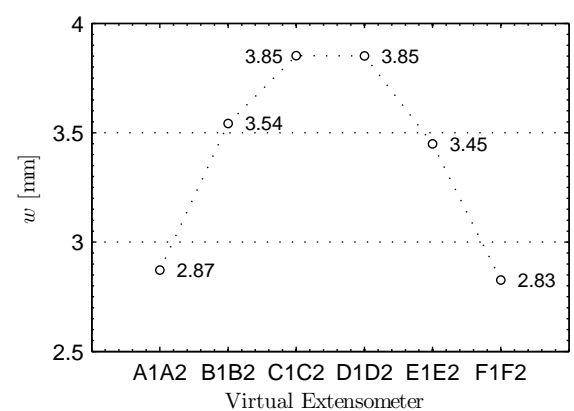

Figure 9: Displacement and deformation analysis of specimen B402: (a) Vertical displacement field $\mathbf{u}_{y}(x, y, z)$ for specimen B402 at $V=217 \mathrm{kN}$; (b) Shear cracking pattern of specimen B402 at failure with indication of drilled cores $(\otimes)$ (note: only shear cracks are presented); (c) Measured crack width $w$ prior to failure at the location of the virtual extensometers; Corresponding nominal stress $\sigma_{N}$ at the location of the virtual extensometers with indication of the $95 \%$ interval

crete beams. Moreover, the three-dimensional displacement field obtained from the stereovision digital image correlation measurements, in combination with the determined material behaviour, revealed that the contribution of the fibre reinforcement is higher than the contribution attributed to the fibres using the current design expressions in Model Code 2010.

It is thus clear that an improved mechanical model is required to accurately estimate the contribution of the provided steel fibre reinforcement. Further research will focus on the numerical simulation of the presented test beams adopting a meso-scale modelling approach where the actual fibre orientation, determined from the experimental structural tests, will be modelled.

\section{REFERENCES}

[1] E. S. Lappa, C. R. Braam, and J. C. Walraven. Bending performance of high strength steel fibre reinforced concrete - static and fatigue loading conditions. Measuring, Monitoring and Modeling Concrete Properties, pages 133-138, 2006.

[2] F. Altun, T. Haktanir, and K. Ari. Experimental investigation of steel fiber reinforced concrete box beams under bending. Materials and Structures, 39(4):491-499, 2006. 
[3] X. C. Fan. Experimental research on bending properties of layered steel/hybrid fiber concrete. Proceedings of International Conference on Health Monitoring of Structure, Materials and Environment, Vols 1 and 2, pages 1024-1027, 2007.

[4] T. Zdeb and J. Sliwinski. The influence of steel fibre content and curing conditions on mechanical properties and deformability of reactive powder concrete at bending. Brittle Matrix Composites 9, pages 33-42, 2009.

[5] J. Michels, S. Maas, A. Zurbes, and D. Waldmann. Bearing capacity of steel fiber reinforced concrete (sfrc) flat slabs in the negative bending moment area and design model for the complete system. Beton- Und Stahlbetonbau, 105(8):496508, 2010.

[6] C. Bywalski and M. Kaminski. Estimation of the bending stiffness of rectangular reinforced concrete beams made of steel fibre reinforced concrete. Archives of Civil and Mechanical Engineering, 11(3):553571, 2011.

[7] G. P. A. G. van Zijl and P. B. K. Mbewe. Towards a design model for steel fiber reinforced concrete in bending. High Performance Fiber Reinforced Cement Composites 6, 2:221-229, 2012.

[8] K. Noghabai. Beams of fibrous concrete in shear and bending: Experiment and model. Journal of Structural EngineeringAsce, 126(2):243-251, 2000.

[9] A. Meda, F. Minelli, G. A. Plizzari, and P. Riva. Shear behaviour of steel fibre reinforced concrete beams. Materials and Structures, 38(277):343-351, 2005.

[10] P. Casanova, P. Rossi, and I. Schaller. Can steel fibers replace transverse reinforcements in reinforced concrete beams? Aci Materials Journal, 94(5):341-354, 1997.
[11] M. di Prisco and L. Ferrara. Hpfrc prestressed thin-webbed elements: some results on shear resistance. In R. de Borst, J. Mazars, G. Pijaudier-Cabot, and J.G.M. van Mier, editors, International Conference on Fracture Mechanics of Concrete Structures, Cachan (France), 2001. Balkema.

[12] J. Rosenbusch and M. Teutsch. Shear design with $\sigma-\epsilon$ method. In B. Schnütgen and L. Vandewalle, editors, RILEM TC 162-TDF Workshop, pages 105-117, Bochum (Germany), 2003. RILEM Publications S.a.r.l.

[13] T. H. K. Kang, W. Kim, Y. K. Kwak, and S. G. Hong. Shear testing of steel fiberreinforced lightweight concrete beams without web reinforcement. Aci Structural Journal, 108(5):553-561, 2011.

[14] A. A. Abbas, S. M. S. Mohsin, D. M. Cotsovos, and A. M. Ruiz-Teran. Shear behaviour of steel-fibre-reinforced concrete simply supported beams. Proceedings of the Institution of Civil EngineersStructures and Buildings, 167(9):544558, 2014.

[15] I. F. Kara. Empirical modeling of shear strength of steel fiber reinforced concrete beams by gene expression programming. Neural Computing and Applications, 23(3-4):823-834, 2013.

[16] M. Shahnewaz and M. S. Alam. Improved shear equations for steel fiber-reinforced concrete deep and slender beams. Aci Structural Journal, 111(4):851-860, 2014.

[17] P. Lava, S. Cooreman, S. Coppieters, M. De Strycker, and D. Debruyne. Assessment of measuring errors in dic using deformation fields generated by plastic fea. Optics and Lasers in Engineering, 47(78):747-753, 2009. 
[18] S. Bossuyt. Optimized patterns for digital image correlation. In SEM International Conference and Exposition on Experimental and Applied Mechanics, Costa Mesa, California USA, 2012. Society for Experimental Mechanics.

[19] K. De Wilder, P. Lava, D. Debruyne, Y. Wang, G. De Roeck, and L. Vandewalle. Experimental investigation on the shear capacity of prestressed concrete beams using digital image correlation. Engineering Structures, 82(1):82-92, 2015.

[20] CEN. Eurocode 2: Design of concrete structures - part 1-1: General rules and rules for buildings, 2004 .

[21] Fédération Internationale du Béton (fib). fib Model Code for Concrete Structures
2010. Wilhelm Ernst und Sohn Verlag für Architektur, Berlin (Germany), 2013.

[22] NBN. Nbn en 1992-1-1 anb, August 2010 2010.

[23] F. Minelli and G. Plizzari. On the effectiveness of steel fibres as shear reinforcement. Aci Structural Journal, 110(3):379389, 2013.

[24] H. Müller, R Breiner, I. Anders, V. Mechterine, M. Curbach, K. Speck, F. Dehn, U. Häussler-Combre, J. Walraven, H.W. Reinhardt, L. Lohaus, N. Oneschkow, C. Gehlen, and R. Beddoe. Code-type models for concrete behaviour. Technical report, Fédération Internationale du Béton (fib), 2013. 